\title{
AUTOETNOGRAFÍA DEL PROYECTO NDER. TRABAJANDO JUNTO A MUJERES AFRICANAS SOBRE CUIDADOS Y MATERNIDAD.
}

\author{
Cristina del Villar-Toribio (Universidad de Sevilla) - mcrviltor@alum.us.es
}

\section{RESUMEN}

Entre 2018 y 2019 participé en el proyecto Nder: Alzando la Voz desde los Feminismos Africanos. Una intervención pionera sobre feminismos africanos en Sevilla, que contaba con la implicación del colectivo de mujeres migrantes africanas. Dentro de las actividades del proyecto, mi compañera Cristina Nuño y yo realizamos un taller sobre Maternidad y Cuidados dirigido a mujeres migrantes africanas. A través de la autoetnografía recojo las reflexiones y conocimientos generados en mi interacción con las mujeres participantes del taller y en un grupo de discusión sobre cuidados que realizamos después del mismo. Cuestiones como afrontar la maternidad en soledad, la desarticulación de las redes de apoyo y de cuidado; el racismo y la discriminación se entrecruzan en el ejercicio cotidiano de los cuidados dando otra mirada hacia la manera de reflexionar sobre las migraciones.

PALABRAS CLAVES: Mujeres, feminismos africanos, cuidados.

\section{RESUMO}

Entre 2018 e 2019, participei do projeto Nder: Alzando a Voz dos Feminismos Africanos. Uma intervenção pioneira sobre feminismos africanos em Sevilha, que teve o envolvimento de um grupo de mulheres migrantes africanas. Nas atividades do projecto, realizei, junto com a minha parceira Cristina Nuño, um workshop sobre maternidade e assistência direccionado para mulheres migrantes africanas. Através da autoetnografia, recolha de reflexões e dos conhecimentos gerados com a minha interação com as mulheres participantes da oficina e de um grupo de discussão sobre os cuidados prestados após a oficina, são abordadas questões como enfrentar a maternidade na solidão, a desarticulação das redes de apoio e cuidados, o racismo, e a discriminação que se cruzam no exercício diário dos cuidados. Este exercício levou novamente a uma análise de como reflectir sobre a migração.

PALABRAS CHAVES: Mulheres, feminismos africanos, cuidados.

\section{PRESENTACIÓN}

Este trabajo tiene como objetivo analizar las experiencias vividas en torno al Taller de Maternidad y Cuidados, dirigido a mujeres migrantes africanas con hijas e hijos. Los objetivos del taller fueron crear un espacio seguro y confidencial para la expresión de las experiencias relacionadas con la maternidad; y fortalecer redes de apoyo informales. Esta actividad formó parte de las acciones realizadas en el proyecto Nder ${ }^{1}$ : Alzando la voz desde

\footnotetext{
${ }^{1}$ Este nombre hace referencia al pueblo de Nder, del norte de Senegal, cuyas mujeres cometieron un suidicio colectivo, encerrándose en una choza y después prendiendo fuego, para evitar caer en las manos de esclavistas moros en 1819. Solo una de ellas, embarazada, se salvó en el último momento y contó la historia de las mujeres de Nder, como un ejemplo de valentia, dignidad y lucha contra la explotación (SERBIN, 2015).
} 


\section{Nanduty}

ISSN:2317-8590

los feminismos africanos, coordinado por la ong Movimiento por la Acción y el Desarrollo en África (a partir de ahora MAD África), y financiado por la Agencia Andaluza de Cooperación Internacional al Desarrollo (AACID), en la ciudad de Sevilla (Andalucía). Este taller se planificó en Sevilla entre los meses de octubre de 2018 y junio de 2019, aunque por motivos relacionados con la organización de las sesiones en coordinación con otras actividades del mismo proyecto se decidió que se concluyera en marzo de 2019.

Al hacer uso de la categoría mujer migrante, es necesario evitar esencialismos y atender a la pluralidad de significados que esta categoría encierra. Esta categoría es una construcción política, en permanente cambio según el contexto económico, legislativo, histórico y político, consecuencia de las grandes desigualdades económicas a escala global. Existe una gran heterogeneidad dentro de este grupo de referencia, debido a diferencias culturales, lingüísticas, educativas o de lugar de procedencia (GREGORIO, 2009). Este caso concreto se centra en mujeres migrantes africanas, entre las cuales también existen diferencias lingüísticas, culturales y educativas. No obstante, tienen otras cuestiones en común como ser migrantes racializadas, de países africanos, que viven en Andalucía, concretamente su residencia habitual es en Sevilla.

El proyecto Nder ha sido una iniciativa pionera en la ciudad de Sevilla, ya que ofertó un curso sobre feminismos africanos dirigido sólo a mujeres africanas. Para facilitar la participación el curso se realizó en horario de tarde y contó con una ludoteca para que las participantes pudieran traer a sus hijas e hijos. Además, se ofrecieron becas para cubrir los gastos de transporte, así como la pérdida de ingresos que pudiera suponer dedicar una tarde en semana al curso en lugar de a otras actividades laborales. A partir de este curso se inició una actividad paralela, un encuentro mensual dedicado a cuestiones relacionadas con la maternidad y los cuidados. La o.n.g MAD Africa contactó con mi compañera matrona, Cristina Nuño y conmigo, psicóloga de profesión, para conducir un taller dirigido a mujeres africanas migrantes con hijas a cargo. Nosotras ya realizamos dos talleres anuales sobre cuidados materno-infantiles de forma conjunta, y yo por mi parte impartí otros tres con anterioridad, dirigidos a mujeres migrantes. 


\section{Nanduty}

ISSN:2317-8590

Los encuentros fueron mensuales, las sesiones ocupaban toda una mañana con una pausa para desayunar juntas. Cristina y yo organizamos las sesiones, alternándonos quién llevaba cada sesión, ella se ocupó de los cuidados de salud reproductiva y lactancia materna, yo me ocupé de los cuidados en la crianza, de la presentación y evaluación de taller. Al taller asistieron de forma regular entre 10 y 4 mujeres, muchas de ellas participaban en otras actividades del proyecto. Aunque este proyecto estaba dirigido a mujeres de países de África sub-sahariana, en alguna de las sesiones del taller de Maternidad y Cuidados participaron dos mujeres marroquíes que tenían interés en asistir al taller. El taller terminó antes de lo previsto, en marzo de 2019, ya que una vez se terminó el curso de feminismos africanos que se realizaba de forma paralela fue más difícil contar con la asistencia mínima de 4 mujeres en las sesiones y decidimos darlo por concluido, contando con el acuerdo del grupo de participantes habituales.

\section{METODOLOGÍA}

En este texto me propongo realizar una autoetnografía, entendida como una metodología que busca, a través de describir una experiencia personal, comprender y describir una experiencia cultural, aplicando los principios de la autobiografía y la etnografía (ELLIS \& ADAMS \& BOCHNER, 2015). Para la composición de esta autoetnografía utilizo notas de campo tomadas durante las sesiones del Taller de Maternidad y Cuidados, fotos, material producido durante los ejercicios, notas de reuniones, recuerdos y preguntas realizadas a posteriori a participantes y colaboradoras. Mi intención es recoger y analizar tanto la información concreta como las epifanías, es decir momentos y relaciones interpersonales que dejan huella en nuestra vida y que alteran las estructuras de significado, organizados de forma retrospectiva (DEZIN, 2017).

La escritura científica no deja de ser una narración, con una autoría, que en este caso representa además una autoridad científica, que analiza, sistematiza y constata una verdad concreta. Esta autoridad tiene la capacidad de perpetuar las relaciones de dominación y desigualdad sino se aplica de manera reflexiva (FELIU, 2007). Por eso creo que es importante destacar que el conocimiento generado en este taller y que yo me dispongo a analizar no es de mi propiedad, es una producción compartida entre las mujeres que participaron en el taller, 


\section{Nanduty}

ISSN:2317-8590

como asistentes o como colaboradoras, tomando como ejemplo estudios como el de Cunha e Sousa (2019), donde en una etnografía sobre la cooperativa de mujeres "Las Capuchinas", las trabajadoras son reconocidas como co-autoras y productoras de conocimiento. La autoetnografía en este caso es una herramienta que me permite deconstruir mi voz como autoridad científica, rompiendo la distancia emocional con las personas de cuyas vidas yo me propongo escribir; escribiendo con y para ellas, incluyendo sus opiniones y saberes, estableciendo un diálogo entre nuestras experiencias comunes y la literatura científica; y haciendo uso de la metodología científica no sólo para constatar verdades, sino para reflexionar sobre sentires diversos y plantear dudas (FELUI 2002 \& REYNOSO 1996).

La autoetnografía ha sido utilizada para describir procesos culturales vividos en primera persona, así como la experiencia vivida a través de la práctica profesional, incluyendo las evocaciones, recuerdos, reflexiones, experiencias y conocimientos adquiridos durante el desempeño de una profesión (DENSHIRE, 2014). En este caso me propongo narrar mi experiencia como psicóloga durante el Taller de Maternidad y Cuidados. No obstante, en mi narración se articulan otras voces, además de mi construcción como profesional de la psicología, también soy investigadora, estudiante de doctorado, feminista. Aunque mi objetivo en el taller no fuese investigar, es una parte de mi que siempre esta presente y modela mi perspectiva. Otras cuestiones identitarias, como el hecho de definirme a mi misma como mujer y feminista (entre otras cosas, que no toman relevancia especial en este texto) contextualizan el lugar desde donde escribo. Es decir, en este texto escribo desde la experiencia como profesional del ámbito de la psicología y como investigadora, como feminista, como mujer, ya que son dimensiones indivisibles, que forman parte de mi misma y por tanto se encuentran igualmente presentes en mi narración.

He escogido tres momentos que considero significativos del Taller de Maternidad y Cuidados para desarrollar este texto. La primera sesión del taller, en la que realizamos un análisis DAFO; la sesión sobre sexualidad; y un grupo de discusión sobre cuidados que realizamos al final de taller, con la intención de elaborar un informe de incidencia política para el Ayuntamiento de Sevilla. Los nombres que aparecen a lo largo de este artículo son los nombres reales de las participantes que me dieron permiso para mencionarlas, ya que 


\section{Nanduty}

ISSN:2317-8590

considero que su aportación no es la de un sujeto experimental, sino la de una co-autoría en la construcción de conocimientos. No obstante, he decido no incluir sus apellidos, para asegurarme de que ninguna de ellas pudiera sufrir ningún tipo de consecuencia negativa inesperada como a raíz de esta publicación. En la sesión de análisis de DAFO participaron mujeres que no dieron su consentimiento expreso para que yo incluyera su nombre, por lo tanto en esa parte me refiero a ellas como participantes.

\section{MUJERES, MIGRANTES, AFRICANAS Y MADRES. UN ANÁLISIS DAFO}

En nuestro primer encuentro organicé varias dinámicas grupales y juegos de presentación, con el fin de conocernos las unas a las otras, asistieron ocho mujeres todas madres, una de ellas estaba embarazada. También participaron Bintou e Isabel, las técnicas de MAD Africa encargadas del proyecto Nder, y mi compañera habitual, Cristina. Comenzamos el primer día con mucha energía, después de las dinámicas de presentación compartimos el desayuno y una vez roto el hielo comenzamos la primera puesta de ejercicio, que fue realizar un análisis DAFO sobre la situación de las mujeres migrantes africanas con hijas/os a cargo en Andalucía. Comencé por este tipo de análisis para conocer mejor a las participantes y sus reflexiones. Decidí contextualizar el análisis a mujeres migrantes en Andalucía, ya que es el territorio donde vivimos y por el que transitamos, algunas de las participantes vivían en Sevilla cuidad y otras en los pueblos de alrededor, pero el tránsito por motivos laborales a otras provincias, manteniendo su residencia en Sevilla es habitual entre muchas mujeres migrantes.

El análisis DAFO, o SWOT por sus siglas en inglés, es un herramienta de diagnostico estratégico ampliamente usada en múltiples contextos por su fácil aplicación y su flexibilidad. Este análisis consiste en realizar de manera conjunta una matriz que indique las debilidades, amenazas, fortalezas y oportunidades (de ahí sus siglas DAFO) de un grupo, en este caso de forma participativa. En esta matriz se ponen en juego dos dimensiones, por un lado cualidades negativas (debilidades y amenazas) y positivas (fortalezas y oportunidades); por otro lado cualidades internas del grupo (debilidades y fortalezas) y externas (amenazas y oportunidades) (PÉREZ CAPDEVILA, 2011). En este caso, el colectivo de participantes tenía en común el hecho de ser mujer, negra, africana, migrante y madre. Desde este espacio de 


\section{Nanduty}

ISSN:2317-8590

intersubjetividad común se desarrollaron las cuatro fases del análisis DAFO y estos han sido los resultados:

\begin{tabular}{|l|l|}
\hline DEBILIDADES & AMENAZAS \\
D1 Soledad & A1 Precariedad laboral \\
D2 Cansancio & A2 Dificultad para acceder a las ayudas sociales \\
D3 Pérdida de roles & A3 Escasez de redes de apoyo \\
D4 Barrera idiomática & \\
D5 Dificultad de conciliación familia-trabajo & \\
\hline FORTALEZAS & OPORTUNIDADES \\
F1 Música & O1 Solidaridad \\
F2 Religión & O2 Atención en salud gratuita \\
F3 Amor maternal & O3 Medios de comunicación \\
F4 Valores y cultura de origen & O4 Nuevas amistades \\
F5 Enseñanzas y filosofía de vida & \\
\hline
\end{tabular}

Tabla 1. Análisis DAFO

\section{DEBILIDADES}

Comenzamos el análisis por las "debilidades". Durante el debate, intento que cada propuesta sea comentada por el grupo de mujeres, y no limitarme a recoger en un trozo de papel opiniones individuales. Las participantes expresaron de manera general la sensación de soledad, el cansancio ante una jornada de trabajo inacabable, la incompatibilidad entre el horario escolar y los horarios laborales. Estas cuestionen resuenan en mi interior y no resultan ajenas al discurso de muchas madres de mi alrededor. Esta situación no es diferente a la que describe Carolina del Olmo (2013), en su obra ¿Dónde esta mi tribu?, en la cual describe la falta de redes de apoyo para la crianza que afrontan las mujeres hoy en día en las ciudades españolas. No obstante, respecto a la soledad, hay una expresión detallada "Aquí estoy sola", "Aquí me siento sola". Este "aquí" nos señala que la soledad a la que hacen frente muchas mujeres, que pasan horas en su casa al cuidado de una o varias criaturas que aún no pueden dejar en la escuela, mientras que su pareja esta fuera, que no tienen familia y amigos cerca. ¿Significa este "aquí" que podría ser de otra manera en otro lugar? Esta es una idea que fuimos retomando en otros momentos. 


\section{Nanduty}

De manera más especifica encontramos dos cuestiones, una es la barrera idiomática, algunas señalan, "no hablo bien, no entiendo, es muy difícil"; y la pérdida de roles "yo aquí no soy nadie". Haciendo un ejercicio de reflexión posterior, "pérdida de roles" fue la manera que mejor encontré de resumen esa sensación que narraba una de las participantes, de pasar de ser "alguien" a ser "nadie". Entrando en detalle, en algunos momentos otras participantes también se habían sentido desvaloradas al perder el papel que tenían en su familia, como tía, hermana, madre, y que aquí, en una vida reducida a la familia entendida como progenitores e hijas e hijos directos, no sólo echan de menos la compañía en sí, sino lo que su red familiar les hacía ser.

\section{AMENAZAS}

Aquí se repite de nuevo las referencias a la soledad, pero en este caso al orientarse hacía el exterior, la discusión giró en torno a "aquí no tengo quién me ayude". Otro gran tema de discusión es la precariedad laboral, ¿qué trabajos puedo encontrar?, salarios bajos, temporalidad, horarios abusivos. Las mujeres que acudieron a esta sesión estaban desempleadas. Una de ellas dejó de asistir porque encontró un empleo dos meses más tarde como limpiadora. Por último, las ayudas sociales, si tienes la residencia puedes intentar pedir alguna ayuda social, no obstante los requisitos son exigentes y las participantes opinaban que son en general difíciles de conseguir.

\section{FORTALEZAS}

Cuando comenzamos hablar de las fortalezas, en este caso descritas como "las cosas que nos hacen seguir para adelante" lo primero que se dijo fue "la música de mi país", las canciones. En un principio yo no entendía bien a qué se refería la mujer que estaba hablando, y explico que se refería a canciones tradicionales, pero que se cantaban en la iglesia. Yo no percibí el sentido religioso detrás de esta afirmación, e iba a continuar anotando sólo la música, pero mi compañera Cristina reparó en que la religión era considerada aquí como una oportunidad, no sólo las canciones. Entonces el resto de mujeres también hablaron de su religión, unas eran cristianas y otras musulmanas, era muy importante en su día a día y una fuente de fortaleza interior. El amor maternal, el amor que ellas sienten por sus hijas/os es considerado también como una gran fortaleza, "un sentimiento tan grande por el que tú haces 


\section{Nanduty}

ISSN:2317-8590

cualquier cosa". Por último estuvimos debatiendo sobre los valores, las enseñanzas lo que te hace ser "una mujer que saca para adelante cualquier cosa". Distinguimos los valores y las enseñanzas del estilo y la filosofía de vida porque ellas distinguían por un lado lo que les habían enseñado, remarcando sobre todo los valores y por otro lado un estilo de vida, aprendido de una manera implícita que les hacía ser mujeres fuertes, capaces de afrontar un proceso duro como migrar de un país a otro.

\section{OPORTUNIDADES}

Por último hablamos de las oportunidades. La solidaridad y el apoyo que encuentran entre las personas de su mismo país de origen, aunque compartan una situación de precariedad laboral, encuentran apoyo las unas con las otras. Un tema que me pareció interesante fue que las participantes hablaran del acceso a la salud gratuito, que si a sus hijas/os les pasaba algo podían llevarlos al médico sin tener que pagar, es un contraste con el resto de oportunidades que tiene una dimensión interpersonal. Los medios de comunicación se refieren al uso de la telefonía movil, las aplicaciones de llamadas IP, mensajería, etc.. que les permiten estar en contacto con su familia. Mandar fotos de sus hijas/os, para que las abuelas las conozcan, llamar a su familia con regularidad, debatimos de que sin esa tecnología su vida como mujer migrante y madre sería más triste. Esta tecnología también les permite poder preguntar las dudas que tienen sobre la crianza de sus hijas/os con otras mujeres de su familia. Finalmente, las participantes hablaron sobre las nuevas amistades que hicieron aquí, con otras personas andaluzas. Estas nuevas relaciones surgieron a partir de sus hijas/os, con vecinas que se acercaron a sus hijas/os o otras madres del colegio. Algunas de ellas compartieron sus historias de amistad y que estas nuevas amistades en les habían permitido conocer mejor la cultura andaluza y practicar más español. En otros casos las nuevas relaciones también implicaron un apoyo en los cuidados de sus hijas/os de forma puntual, es decir, tener a alguien de confianza a quién dejar a sus hijas/os en caso de necesidad. 


\section{HABLANDO SOBRE SEXUALIDAD, LA IMPORTANCIA DE LLAMAR A LAS COSAS POR SU NOMBRE}

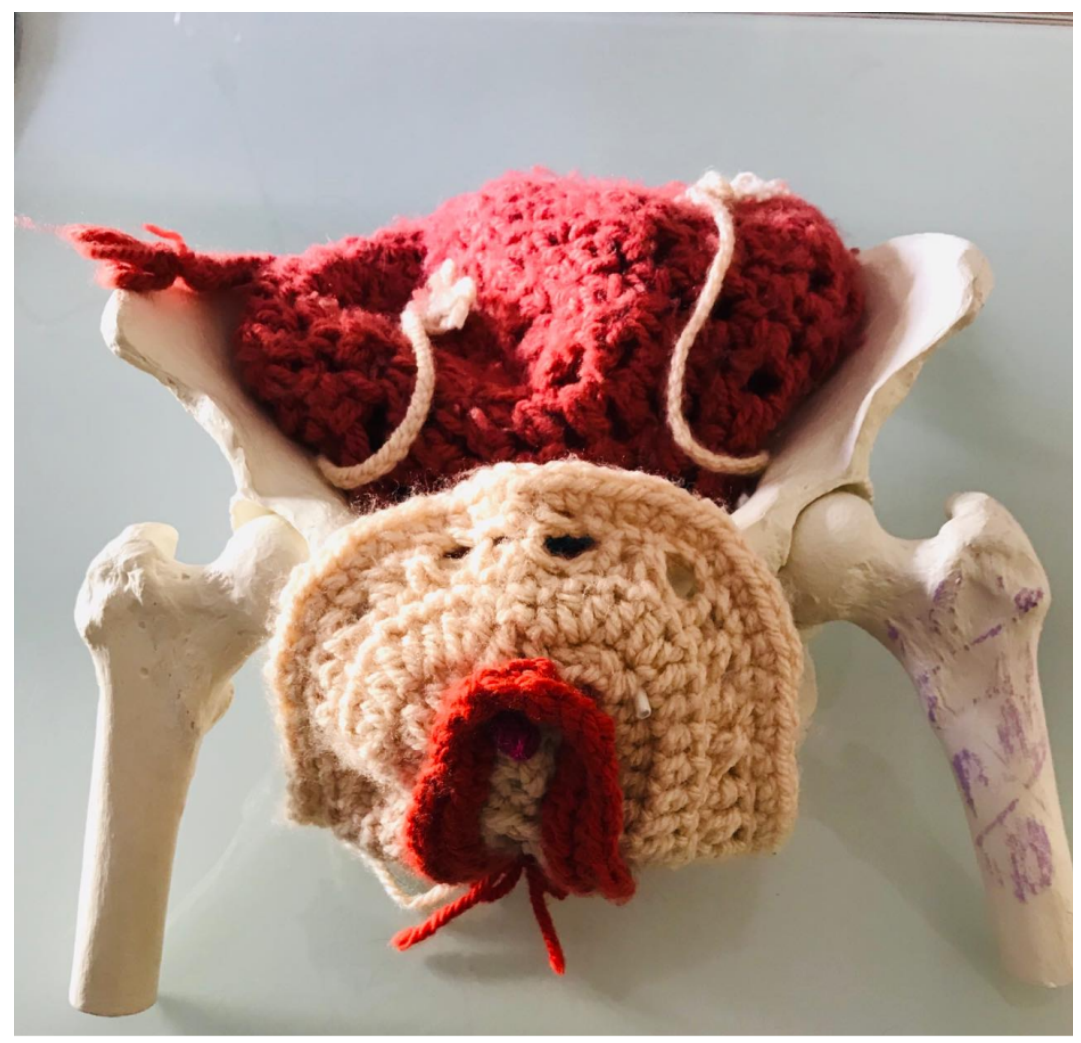

En el mes de enero de 2019 realizamos una sesión sobre sexualidad $\mathrm{y}$ planificación familiar. Fue un día lluvioso y frío, la lluvia en Sevilla es una maravilla dice el refrán, y sin duda lo es, pero también es la peor enemiga de cualquier actividad asociativa, ya que sea una sevillana por vocación o por obligación, la lluvia en esta ciudad te invita a quedarte en casa, en la

Imagen 1, Construcción de genitales femeninos vista exterior.

mesa camilla calentita, como si fuera azufre en llamas y no agua lo que cae del cielo. Por eso ese día solo nos juntamos cinco mujeres, Cristina que conducía el taller, Mariette, educadora de un centro que atiende a mujeres solicitante de asilo, Bintou, técnica de MAD África, Sophie, amiga y habitual de nuestro taller de madres y yo misma. Comenzamos con el desayuno, charlamos, esperamos a ver si alguna más aparecía. Para este día Cristina trajo una pelvis de plástico a que ella misma cosió un útero, una vagina, una vulva, con un clítoris desmontable acompañado de un muñeco, todo ello en ganchillo y de vivos colores; trajo fotos de folículos y óvulos; dibujos del endometrio; y hasta una lámina con los arquetipos femeninos de Miranda Gray (1995). Debido a la escasa asistencia, nos pusimos en circulo y dejamos de lado las láminas más técnicas, nos dedicamos a compartir nuestras experiencias relacionadas con nuestra menstruación y nuestra sexualidad. Todas realizamos un ejercicio que nos enseñó Cristina para calcular nuestros días fértiles, hablamos de en qué momento de 


\section{Nanduty}

ISSN:2317-8590

nuestro ciclo sentíamos más ganas de mantener relaciones sexuales, de como cada una sentía sus periodos y cómo habían cambiado a lo largo de la vida. Esa sesión fue la más distendida y la más personal, olvidamos el taller, olvidamos los folículos y los endometrios para ser un

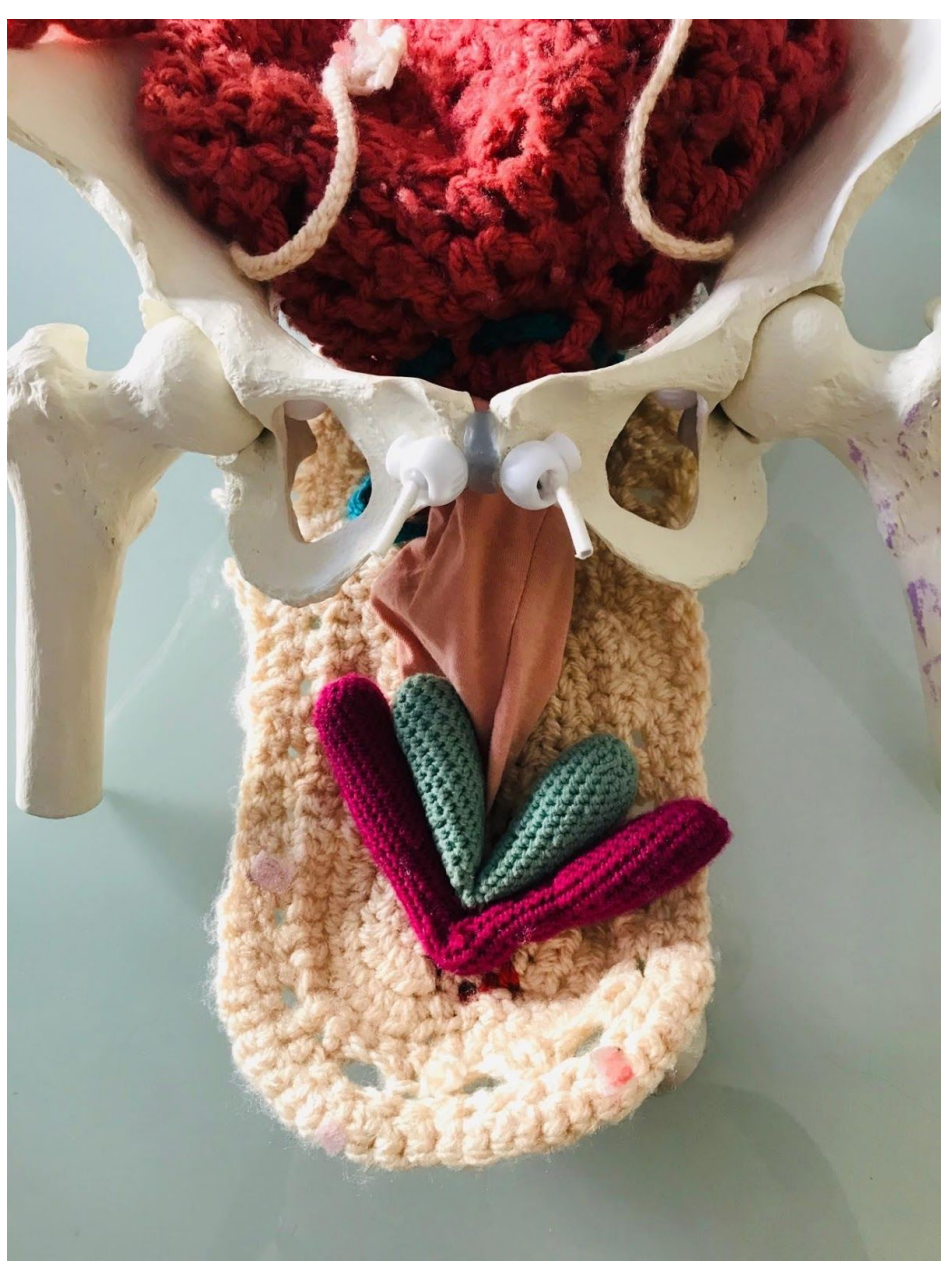
grupo de amigas tomando café con galletas mientras hablábamos de nuestras cosas un día de lluvia. Esto me hizo pensar en la complejidad excesiva con la que a veces nos planteamos el tratamiento de la sexualidad desde la mediación intercultural y que con una relación de confianza construida previamente abordar la temática de la sexualidad es mucho más simple, y más ameno también. Mientras admirábamos la creación de Cristina, la pelvis de plástico con los órganos sexuales de crochet, hablamos sobre la higiene de nuestra vulva/vagina, y la

Imagen 2. Construcción de genitales femeninos, vista interior

confusión que producen esos términos. Es común encontrar la palabra vagina (parte interna del órgano sexual femenino) cuando en realidad se refiere a la vulva (parte externa). Esto nos causaba confusión a todas, incluso en esta sesión, sino hubiéramos tenido la pelvis delante no habríamos reparado en que cuando unas hablaban de la higiene de la vagina, se referían a la parte interna, y que otras nos referíamos a la parte externa de nuestros genitales. Fue un momento en el que comenzó a aumentar el interés por la pelvis de Cristina y de llamar a las 


\section{Nanduty}

ISSN:2317-8590

cosas de por su nombre. El momento verdaderamente revelador para mi, y cómo traté después para mi compañera Cristina también, fue cuando ella después de mostrar la punta del clítoris a través de los labios menos sacó la pieza entera, mostrando el clítoris en su totalidad. En ese momento Sophie dijo "Ah, entonces no te lo quitan todo".

Ninguna de las 5 habíamos reparado en esto, la llamada mutilación genital femenina no supone la extirpación completa del clítoris, sino de su cabeza visible, en algunos casos también de los labios menores, pero nunca del clítoris completo. No pretendo, en ningún momento restar gravedad a esta práctica que atenta contra la salud y el bienestar de muchas mujeres, sino mostrar cómo este comentario nos dio la oportunidad de mirar las cosas desde otro prisma, y que como mujeres andaluzas, europeas, probablemente nunca hubiéramos reparado en esto. En los cinco años en los que me dediqué a organizar talleres sobre maternidad y cuidados con mujeres migrantes, todos y cada uno de los años, tuve propuestas por parte de otras mujeres españolas para dedicar una sesión sobre la mutilación genital femenina (MGF). Creo que esto se debe a una sobrerepresentación de la MGF en proyectos de cooperación internacional en el continente Africano, en jornadas sobre migración y cuestiones de género relacionadas con Africa y en las formaciones de competencia cultural en salud. Por ello, la asociación entre mujer africana y MGF esta fuertemente construida en nuestro imaginario y se convierte en una propuesta recurrente.

Hasta ahora siempre me negué a realizar un taller sobre esta temática por dos razones. La primera es porque la MGF es una práctica heterogénea, asociada a diversas tradiciones culturales y practicada de diferente manera y ajena a mí. Creo que es a las propias mujeres africanas a quienes corresponde discutir sobre MGF y no a mí, ni a otras compañeras no africanas. Por lo tanto un taller sobre este asunto debería ser propuesto y coordinado por una(s) mujer(es) africana(s) y nosotras, en todo caso, seriamos colaboradoras. Creo que es fundamental como feminista reconocer también los privilegios derivados de la raza y el origen y aceptar las críticas al feminismo occidental hegemónico, lo supone en la práctica saber estar en un lado, en la segunda fila, o en otras palabras: callar y que hablen otras (CUNHA, 2017). La segunda razón, es lo que yo llamo los mantras asociados a la mutilación genital femenina. 


\section{Nanduty}

El primer mantra: la inmigración africana ha traído a Europa, un paraíso de los derechos de la mujer, la MGF, una "expresión cultural de la violencia de género" (GRANDE-GASCÓN, RUIZ-SEISDEDOS \& HERNÁNDEZ-PADILLA, 2013). Según la OMS (2005) la MGF se define como "todos los procedimientos consistentes en la resección parcial o total de los genitales externos femeninos y otras lesiones de los órganos genitales femeninos por motivos no médicos". En esta definición se podría incluir la vaginoplastia, labioplastia, himenoplastia, la luposucción del monte de Venus y toda la llamada cirugía de rejuvenecimiento vaginal. Me pregunto, ¿por qué estas operaciones no se consideran un expresión cultural de la violencia de género? ¿por qué no se consideran una mutilación?. La hipótesis de que estas intervenciones sean realizadas por un/a profesional de la medicina no es válida en este caso, ya que según un informe publicado por UNICEF (2012) con estadísticas tomadas entre 2008 y 2011 indica que en países como Egipto, uno con mayores tasas de MGF, la intervención es realizada en casi un ochenta por ciento de los casos por profesionales de la medicina. Las diversas creencias que sustentan la práctica de la MGF sin duda son creencias patriarcales que vulneran los derechos de la mujer, pero yo como mujer europea estoy más preocupada por las creencias que sustentan la idea de que una mujer tiene que someterse a un procedimiento quirúrgico para rejuvenecer sus genitales. Me preocupa que estas prácticas se consideren una opción médica válida, creo que las mujeres que se someten a este tipo de intervenciones están influenciadas por las creencias machistas que dictan que la mujer no es dueña de su sexualidad, que su placer no importa, no existe, sino que esta para complacer al hombre, como ocurre con la MGF en los países africanos. En este caso, las intervenciones quirúrgicas para el rejuvenecimiento vaginal, para conseguir una vagina "prieta" y "bonita", al gusto de los hombres, es el machismo de los míos, por lo tanto una opción válida.

Por otro lado, los rituales de paso femininos en los que se práctica la escisión total o parcial del clitoris y labios menores, el machismo de los otros, es barbarie, la mutilación. Mi objetivo con esta comparación no es equiparar las prácticas asignadas como MGF a la cirugía de rejuvenecimiento vaginal, sino poner en evidencia como la similitud entre ambas, tanto en la práctica en si (cortar, mutilar, retirar) como en los discursos que las mantienen (sexualidad 


\section{Ñanduty}

ISSN:2317-8590

femenina servicio del placer masculino) quedan invisivilizadas por la mirada colonial sobre las prácticas africanas. La MGF es una cuestión relacionada con las mujeres, por lo que es relevante que sea analizada desde una perspectiva feminista, pero urge realizar también una visión crítica postcolonial sobre la mirada occidental a la MGF y su consecuencia en los protocolos y programas de prevención (WEDRUNA; REIMER-KIRKHAM; EWASHEN, 2016).

La afirmación incompleta de que la MGF llegó a Europa con la inmigración africana, además de criminalizar la migración, refuerza la representación estereotipada de la mujer migrante como víctima pasiva de su propia cultura (GREGORIO, 2012).

El segundo mantra: las niñas africanas están en peligro. El día seis de febrero se celebra la efeméride del día contra la MGF. Ese día suele ser habitual encontrar en la prensa española la noticia de que 18.000 niñas en España aproximadamente están riesgo de sufrir una MGF (RIEACO, 2019; ABC, 2018; EL PERIÓDICO 2018; NUEVA TRIBUNA 2018; EL PLURAL 2018; MOUZO, 2017; RENGEL, 2017). Estas cifras atienden a los indicadores de edad, tener menos de catorce años y ser de origen de uno de los 29 países africanos donde se práctica la MGF. Todas las noticias destacas el peligro de los viajes al país de origen, aunque se han documentado casos en los que la mutilación se produjo en España. La MGF es un delito penal en España, por lo cual estos titulares susurran entre líneas que los progenitores de 18.000 niñas son sospechosos de incurrir en un delito grave. Esta estadística no atiende ni la prevalencia de esta practica en cada país ni los indicadores de riesgo de sufrir una MGF de cada país. Considera igual de arriesgado las vacaciones de una familia de Togo (con una prevalencia de MGF en niñas de 0 a 14 del 0,4%, según UNICEF) que de Gambia (56\% de prevalencia en niñas de 0 a 14 años según el mismo informe).

Encontramos varios programas para la prevención de la mutilación femenina en España, protocolos de actuación a nivel sanitario, educativo, policial y de mediación intercultural. Estos programas están dirigidos a niñas menores de catorce años con padres provenientes de uno de los veintinueve países donde se práctica la mutilación genital femenina. Los protocolos incluyen medidas como realizar un examen genital a las niñas después de realizar un viaje a su país, observar algún inicio de que se haya realizado una mutilación como 


\section{Ñanduty}

ISSN:2317-8590

malestar, incomodidad aparente en la zona genital, cambios en el comportamiento, sobre todo después de un viaje a su país de origen (LUCAS, 2008). También existe en algunas comunidades autónomas un modelo de compromiso de no mutilar a tu hija durante las vacaciones para que lo firmen antes de viaje (ALCÓN BECHI et al. 2013; KAPLAN et al., 2006). Excepto el examen genital, que correspondería exclusivamente a los profesionales de la salud, me siento incapaz de llevar acabo ninguna de las otras medidas y mantener una coherencia profesional desde el respeto y la empatía. Especialmente, el protocolo relacionado con el compromiso de no mutilación, práctica análoga a la del personal de seguridad de los aeropuertos, obligados a preguntar si llevas explosivos en tu equipaje. Estoy a favor de que existan programas de prevención de la mutilación genital femenina, pero no considero útiles en mi práctica profesional estos protocolos. Los casos de MGF documentados en España son menores que los de otras violencias que sufren las mujeres africanas en España (por ejemplo, violencia de género). Según un informe de la Delegación del Gobierno para la Violencia de Género sobre la MGF en España se citan ocho casos de MGF femenina, tanto realizados en España, como en el país de origen las víctimas entre 1993 y 2014. No existen estadísticas que den una cifra exacta de los casos de MGF en España, no obstante afirmar que 18.400 niñas están peligro de sufrir MGF, por el hecho de tener 14 años y proceder de uno de los 29 países africanos donde se práctica, es arriesgado y alarmista.

Creo que es preciso hacer el ejercicio de llamar a las cosas por su nombre sobre el tratamiento de la mutilación genital fémina en la práctica profesional con mujeres migrantes africanas. La mutilación genital femenina no es un fenómeno exclusivamente africano, existe una MGF “a la occidental”, en Europa, como en África, muchos hombres devalúan la sexualidad femenina, e imponen su derecho al placer por encima del nuestro. No me importa el número de hombres, europeos o africanos, que niegan a las mujeres el derecho a vivir su sexualidad, me importan las consecuencias que tienen en la vida de las mujeres. Los esfuerzos nacionales de lucha contra la mutilación genital femenina no están dirigidos a mujeres africanas, están dirigidos a clítoris cortados por otros. Las mujeres solicitantes de asilo que han sufrido una MGF están igual de desamparadas las solicitantes de asilo que a día de hoy duermen en la calle por falta de plazas en los centros de acogida. Las niñas africanas 


\section{Nanduty}

ISSN:2317-8590

en Europa corren mayor peligro de ser víctimas del racismo, la discriminación y la violencia de género, que de sufrir una MGF y cuando leo, ya sea prensa o publicaciones científicas, no es ese el discurso que encuentro.

\section{GRUPO DE DISCUSIÓN SOBRE CUIDADOS}

Una vez acabado el taller de Maternidad y Cuidados comenzó la elaboración de un informe sobre cuidados y mujeres migrantes africanas para presentarlo en el Ayuntamiento de Sevilla, como una de las actividades del proyecto Nder. Como no llegó a celebrarse la sesión de evaluación del Taller de Maternidad y Cuidados, consideré que tenía poco material para realizar el informe y llamé a una amiga, Fatou, que participó en el taller para preguntarle si consideraba alguna cosa que yo debiera incluir en este informe. Ella sugirió que lo mejor sería hacer una discusión en su casa, ya que cerca de ella vivían otras tres mujeres que participaron en el taller y que entre las cinco recogiéramos los temas importantes a presentar en el Ayuntamiento. Una de las mujeres no pudo venir, nos juntamos Fatou (Senegal), Latifah (Nigeria) Zoueba (Togo) y yo, una mañana de octubre de 2019 en casa de Fatou.

He dividido el resumen de la discusión que tuvimos en tres partes, que fueron los tres temas de los que hablamos. Las dificultades para conciliar los horarios laborales y escolares, las experiencias relacionadas con los cuidados en los viajes a sus países de origen y los cuidados en salud.

\section{a) Conciliación trabajo-escuela}

Cuando comenzamos a hablar sobre cuidados, ¿de qué cuidados nos ocupamos en nuestra vida diaria? ¿cómo los vivimos?, lo que primero que sale es lo difícil que es ocuparse de los cuidados básicos de las/os hijas/os y de una misma porque ni el tiempo disponible ni el dinero dan como para organizar las labores de cuidados necesarias de forma cómoda. Zoeba tomó primero la palabra, es la más mayor de las cuatro, tiene dos hijos nacidos en España y su discurso claro, directo y muy potente.

No hay un trabajo que te permite llevar y recoger los niños al cole, son 7 o 8 horas, o trabajo de noche.

O trabajo o cuido de mis hijos, las dos cosas es complicado de hacer sola. Estas dificultades de conciliación de horarios son comunes para toda la población andaluza. No 


\section{Nanduty}

ISSN:2317-8590

obstante, las mujeres migrantes africanas señalan que en este caso su situación se complica por la carencia de redes de apoyo, como una familia extensa cerca, que les apoye en las labores de cuidado de las hijas. Cuenta como cuando ella y su marido trabajan la solución que encuentran es intentar inscribir a sus hijos en las actividades destinadas a la conciliación familiar, que son aulas matinales, horario especial de los centros escolares a partir de las siete de la mañana y comedor escolar, que puede ser hasta las tres o hasta las cuatro de la tarde. No obstante, estos procesos de inscripción son difíciles. Zoueba dice:

Los aulas matinales y comedor te coge solo si madre y padre están de alta, porque aquí todo el mundo trabaja pero no todo el mundo esta de alta. Y tarjeta de residencia, ¿qué tiene que ver la tarjeta con los niños que nacieron aquí?.

Tanto Zoueba como Latifah consideran injusto tener que entregar la tarjeta de residencia de las hijas para acceder a los servicios de comedor y de aula matinal, especialmente cuando sus hijas han nacido en España, y viven este procedimiento como un acto de discriminación. También critican el exceso de documentos que se les requiere para estos servicios en general. Andalucía es una de las comunidades autónomas de España con una mayor economía sumergida, sobre todo en trabajos relacionados con la hostelería, la agricultura, la limpieza y los cuidados, sectores donde trabajan muchas personas migrantes.

La educación en España es obligatoria a partir de los seis años y pública y gratuita a partir de los tres. Existen centros educativos públicos para criaturas de entre cero y tres años subvencionadas por el gobierno regional, en este caso la Junta de Andalucía. Estos centros son más económicos que los centros privados y pueden estar subvencionados según las condiciones de cada familia. Para acceder a una plaza de un centro de este tipo es necesario que tanto la criatura como los dos progenitores tengan la tarjeta de residencia vigente. Latifah explica:

Yo metí a mi hija con 5 meses, pero la tuve que dejar, me daba pena, y ese año no trabaje hasta el siguiente año. Aula matinal, lo mas difícil. Pa la guardería te piden residencia de los tres, si estas trabajando, libro de familia, ingresos, padrón...

No es fácil para todas las mujeres dejar a sus criaturas tantas horas al cuidado de otras personas, en este caso Latifah prefirió perder su trabajo y esperar un año. Las dificultades para tener la documentación en regla se unen a la falta de redes de apoyo, la falta del calor de la 


\section{Nanduty}

ISSN:2317-8590

familia que dejaron atrás. Hablando sobre la situación concreta ellas como migrantes Zoueba dice:

Y cuando me preguntan: ¿Tu estas aquí mejor que en tu país verdad? Mejor que en mi país estará tu puta madre. Yo veo supervivientes (no migrantes), ¿cómo vamos a vivir mejor aquí? ¿Sin la familia?

Supervivientes en vez de migrantes, esta frase de Zoueba resuena en mi cabeza contra el discurso de migrantes económicos versus refugiados que ha tomado fuerza en la escena política española a partir de la llamada crisis de refugiados de 2015. A nivel de intervención social, también las convocatorias de proyectos y las partidas presupuestarias están separadas entre migrantes y solicitantes de asilo. Pero más allá de la diferencia administrativa para conseguir el estatus de residente ¿dónde esta la diferencia entre un grupo y otro? ¿realmente vamos a dar por válida la explicación de que quién emigra lo hace porque quiere?. Situaciones como esta me hacen cuestionarme la voluntariedad de iniciar un viaje migratorio sur-norte. En el relato de Zoeuba no hay grandes expectativas, deseo de triunfo ni sueños de grandeza, deja explícito el desarraigo que siente al estar lejos de su familia, una parte fundamental de su vida.

\section{b) Cuando estoy allí, cuando estoy aquí.}

Durante la primera parte de nuestra discusión Fatou apenas intervino, estaba de una lado para otro de su casa, cargando cajas y bolsas, preparando el viaje a Senegal que iba a realizar con sus hijos en unos meses. Aprovechando el viaje que un amigo iba a hacer en coche desde Sevilla, preparó una maleta con cosas para que llevara a la casa de su familia en Senegal. Zoueba estuvo de vacaciones durante el verano en Togo con sus hijos, Latifah también tuvo la oportunidad durante este año de hacer una visita a Nigeria para que su familia conociera a su hija de dos años. Zoueba cuenta lo tranquila que estaba en casa de su familia, lo mucho que pudo descansar, lo rica y sabrosa que estaba la comida. Ella deja claro que si pudiera volvería allí para quedarse. Latifah cuenta que aquí, en España esta casi todo el día sola con su hija y cuando fue a Nigeria notó mucha diferencia:

Estuve un mes en mi país y casi no cargué a mi niña en brazos. 


\section{Nanduty}

ISSN:2317-8590

Después de varios años viviendo en España, Latifah su hija y su marido se van a vivir a Reino Unido, donde ella tiene familia, sus padres y varios hermanos viven allí. El día de la discusión se cruzaron la vuelta del viaje de Zoueba, el viaje inminente a Reino Unido de Latifah (dos días después de nuestra reunión), los preparativos del viaje de Fatou y mi visita a Sevilla, pues también vivo fuera de España actualmente. Todas hablamos que esta difícil la vida en la ciudad, los precios del alquiler están por las nubes, el estado de las viviendas que tienen aun un precio asequible suele ser pésimo. Fatou misma, además de preparar su viaje, esta preparando su mudanza, se va del barrio, el dueño va a reformar su piso para venderlo y no encuentra piso en su barrio, se va a uno a las afueras de la ciudad:

A una casa más cara y más chica.

Encontrar un alquiler asequible en Sevilla es un desafío, en eso estamos todas de acuerdo, pero muchos propietarios de pisos se muestran reacios a alquilar a migrantes, y Zoueba apunta:

Esta difícil el alquiler si, sobretodo si eres negra.

Cuando Latifah y Zoueba se fueron, me quedé a almorzar con Fatou y me estuvo contando los pormenores de su viaje a Senegal, va a ser la primera vuelve a su país desde que llegó a España, va a presentarles a sus hijos de cinco y dos años a su familia:

Yo quiero llevar a mis hijos allí un tiempo, que ellos aprendan la lengua (wolof) y la religión de nosotros (islam) ¿sabes?. La niña ya esta cogiendo cosas de aquí y no quiero" Explica que llamo su hija mentiroso a su tío."Eso una niña de aquí lo puede hacer, pero mi hija no va a decir mentiroso a un tío suyo. Quiero que se queden allí un tiempo con mi familia, para que cojan las cosas de allí. Y así yo también poder trabajar, que llevo años que no puedo hacer nada, este verano a Lepe me los lleve a los dos y eso no es lugar para niños. Yo quiero tener un tiempo, seis meses, para yo solo trabajar, ahorrar dinero y luego ir a estar con ellos a mi país.

Fatou llegó a España hace diez años a trabajar como temporera recogiendo fresas en Huelva, salvo algún trabajo puntual como vendedora de comida ambulante o limpiadora su trabajo en España ha sido en la agricultura. También su marido alterna la venta ambulante con hacer "las temporadas", recogiendo aceitunas, naranjas, depende de cada estación. Fatou trabaja en la fresa, una labor agrícola fuertemente feminizada (GUALDA CABALLERO, 2012). Me cuenta que quiere que sus hijos pasen una temporada en su país con su familia, 


\section{Nanduty}

ISSN:2317-8590

para que aprendan la cultura y para que ella tenga tiempo para trabajar. Ella no quiere dejar a sus hijos con cualquiera, tiene miedo de tener problemas porque en los últimos años se han dado casos de familias senegalesas que perdieron la custodia de sus hijos por dejarlos al cargo de una familia española durante un periodo de tiempo. Ella a veces se queda algunas semanas con el hijo de una amiga, mientras ella viaja, pero no se ve capaz de hacer lo mismo, se siente más segura si es su familia quien los cuida. Deja a los niños al cuidado de su marido cuando tiene que salir, ella negocia con él para que se implique en las labores de cuidado con sus hijos, pero ve en él un apoyo puntual, ya que él trabaja fuera de casa la mayor parte del día, y no se implica en los cuidados de la misma manera que ella:

Llevo a casa y le pregunto ¿Han comido los niños?, él me dice sí han comido. Le pregunto a los niños, ¿Qué habéis comido? Gusanitos ${ }^{2}$ me dicen. Eso un día vale, pero una semana no.

Estos tres viajes, serían considerados por los protocolos sobre MGF antes mencionados como un indicador de riesgo. No obstante, si las familias migrantes contarán con una atención integral, donde el objetivo fuera establecer relaciones de confianza y garantizar sus derechos básicos estos protocolos no serían necesarios. La diferencia entre lo que ellas cuentan sobre sus experiencias y expectativas durante las visitas puntuales a su familia y sus experiencias como madres migrantes respecto a los cuidados indican una desarticulación de la red de cuidados durante el proceso migratorio.

\section{c) Cuidados en salud}

En general los servicios para el cuidado de la salud son valorados positivamente, tanto en la atención a sus hijas como a ellas mismas. Por otro lado, han sentido discriminación por el hecho de ser mujeres africanas en los servicios de salud. Zoueba cuenta un problema que tuvo con su médica de familia:

La médica me amenazó con denunciar porque el niño se cayó de la cama [el niño fue al médico con un golpe en el brazo que se hizo al caerse saltando en la cama], me dijo que no se podía subir en la cama, si volvía a caerse que me denunciaba.

Ella identifica claramente esta sospecha de maltrato al hecho de ser migrante, africana y negra. En general siente que la tratan como si fuera una mala madre, o negligente, cómo si no

\footnotetext{
${ }^{2}$ Snack salado hecho con maíz
} 


\section{Nanduty}

ISSN:2317-8590

supiera cuidar de sus propios hijos cuando es atendida por los servicios de salud. Por otro lado, la competencia cultural del personal de salud percibida por ellas se limita a hablarles alto o preguntarles si han entendido sus instrucciones. La formación en competencia cultural sigue siento un asunto pendiente a tratar entre los profesionales sanitarios (RAIGAL-ARAN, RIFA-ROS, BORRUEL-LLOVERA \& FERRE-GRAU, 2017). Sin embargo, es de señalar que la formación en competencia cultural debería incluir cuestiones relacionadas con el racismo y la mentalidad colonial, ya que como vemos en este ejemplo existen una tendencia a la infantilización de la población africana.

$\mathrm{O}$ te pregunta 20 mil veces si entiendes, te explica las cosas y te pregunta todo el rato, ¿entiendes? ¿Cómo no voy a entender si el niño lo he parío yo?. O decirte ¿has echo bien lo que te dicho? Es como que mi niño sigue malo porque yo soy africana negra y no entiendo ni se hacer las cosas bien. Pareces su hija cuando te hablan.

No obstante, las tres tienen estrategias para afrontar situaciones de discriminación como poner una reclamación, acudir a una colectivo de personas migrantes para informarse de sus derechos o simplemente cambiar de médico y solicitar otro del que previamente se han informado. Entre ellas, hablando del centro de salud más cercano comparten información sobre el trato recibido por los diferentes médicos, Fatou nos contó:

La medica buena es una que esta en África mucho tiempo, nosotras nos cambiamos a esa cuando nos hablaron de ella.

\section{CONCLUSIONES ${ }^{3}$}

En resumen, las cuestiones relacionadas con los cuidados que más preocupan a la mujeres migrantes africanas que viven en Sevilla son sus dificultades para la conciliación entre el trabajo y las labores de cuidados, debido a factores como la precariedad laboral, la incompatibilidad de horarios laborales y escolares y la dificultad para acceder a los recursos para la conciliación como guarderías, aulas matinales y comedores escolares. Facilitar el acceso a estos recursos supondría un aumento del bienestar tanto de las mujeres migrantes africanas como de sus hijas. Por ello, estos datos ponen en relieve la necesidad de garantizar la igualdad de derechos de menores y adolescentes de familias migrantes.

\footnotetext{
${ }^{3}$ Esta investigación se llevó acabo en el marco del proyecto financiado por el Gobierno de España [PSI2016-80112-P], llamado Desafíos del yo: Reconstrucción de las Identidades en Situaciones de Desigualdad y Exclusión Social.
} 


\section{Nanduty}

ISSN:2317-8590

Otra cuestión importante es la falta de redes de apoyo en las labores de cuidados, una carencia que las mujeres migrantes africanas intentan afrontar mediante estrategias como fortalecer los vínculos con su comunidad de origen, exigir co-responsabilidad en las labores de cuidados a sus parejas y establecer nuevas redes de apoyo social, principalmente en la escuela y el vecindario. Por lo tanto, sería adecuado prestar atención a estas estrategias desarrolladas por las mujeres migrantes africanas a la hora de diseñar e implementar proyectos de intervención relacionados con la igualdad de género y los cuidados, evitando caer en la idea estereotipada de la mujer africanas como víctimas de su propia cultura.

\section{REFERENCIAS BIBLIOGRÁFICAS}

ABC. 2018. Más de 18.000 niñas pueden sufrir la mutilación genital en España, según ONGs.

https://www.abc.es/sociedad/abci-mas-18000-ninas-pueden-sufrir-mutilacion-genital-espana-s egun-ongs-201802061045 noticia.html (acessado em 10 de fevereiro de 2020).

ALCÓN BELCHÍ, C., et al. 2016. Algoritmo de actuación en la prevención de la mutilación genital femenina. Estudio de casos desde atención primaria. Atencion Primaria, Barcelona, 48(3): 200-205.

CUNHA, Teresa. 2017. "Todo o trabalho é produtivo: economias de abundância e da sobriedade.”, In: GONZÁLEZ, Hermida X. (coord.). [Re]Pensar a democracia. Compostela, Obencomún: 101-134.

; SOUSA, Vanessa. 2019. Epistemologías del Sur y las Economías de Ellas. La Cooperativa "Capuchinhas" de la Sierra de Montemuro. Revista de Antropologia Social, Madrid, 28(2): 323-344.

GREGORIO GIL, Carmen. 2009. Mujeres inmigrantes: colonizando sus cuerpos mediante fronteras procreativas, étnico-culturales, sexuales y reproductivas. Viento Sur, Madrid, (104):42-54.

DEL OLMO, Carolina. 2013. ¿Dónde esta mi tribu? Maternidad y crianza en una sociedad individualista. Madrid, Traficantes de Sueños.

DENSHIRE, Sally. 2014. On auto-ethnography. Current Sociology Review, Londres, 62(6): 831-850.

LUCAS, Bénédicte. 2008. Prevención de la ablación o Mutilación Genital Femenina en España: Planes de acción y medidas de protección de menores, complementos necesarios a la prohibición legal. Cuadernos Electrónicos de Filosofía Del Derecho, 17(5):1-18.

KAPLAN MARCUSAN, Adriana, et al. 2006. Genital mutilation of women: Reflections for a primary care intervention. Atencion Primaria, Barcelona, 38(2):122-126.

GRANDE-GASCÓN, María-Luisa; RUIZ-SEISDEDOS, Susana; HERNÁNDEZ-PADILLA, María. 2013. El abordaje social y político de la mutilación genital Femenina. Portularia, Huelva, 13(1):11-18.

GUALDA CABELLERO, Estrella. 2012. Migración circular en tiempos de crisis. Mujeres de Europa del Este y africanas en la agricultura de Huelva. Papers, Barcelona, 97(3):613-640. 


\section{Nanduty}

ISSN:2317-8590

ELLIS, Carolyn.; ADANS, Tony E.; BOCHNER, Arthur P. 2015. Autoetnografía: un panorama. Astrolabio Nueva Época: Revista Digital Del Centro de Investigaciones y Estudios Sobre Cultura y Sociedad, Córdoba, 0(14):249-273.

EL PERIÓDICO. 2018. Más de 18.000 niñas que viven en España corren el peligro de sufrir la ablación.

https://www.elperiodico.com/es/sociedad/20180205/mas-de-18000-ninas-que-viven-en-espan a-corren-el-peligro-de-sufrir-la-ablacion-6603178 (acessado em 12 de fevereiro de 2020). EL PLURAL. 2018. Unas 18.400 niñas están en riesgo de sufrir mutilación genital femenina en

España.

In:

https://tribunafeminista.elplural.com/2018/02/unas-18-400-ninas-estan-en-riesgo-de-sufrir-mu tilacion-genital-femenina-en-espana/ (acessado em 12 de fevereiro de 2020).

DENZIN, Norman K. 2017. Autoetnografía Interpretativa. Investigación Cualitativa, 2(1):81-90.

FELIU I SAMUEL-LAJEUNESSE, Joel. 2007. Nuevas formas literarias para las ciencias sociales: el caso de la autoetnografía. Athenea Digital: Revista de Pensamiento e Investigacion Social, Barcelona, (12):262-271.

2002. L'esclat de la diversitat. Les propostes de la postmodernitat. A Agustí Andreu i Jordi Pascual (coords.). Diferències humanes $i$ diversitat. Barcelona, Editorial UOC.

MOUZO QUINTÁNS, Jessica. 2017. Más de 18.000 niñas están en riesgo de sufrir mutilación genital en España. El País. https://elpais.com/ccaa/2017/11/22/catalunya/1511359078 457060.html (acessado em 12 de fevereiro de 2020).

PÉREZ-CAPDEVILA, Javier. 2011. Óbito y resurrección del análisis DAFO. Avanzada Cientifica, 14(2):1-11.

RAIGAL-ARAN, Laia; et al. 2017. Revisión sistemática sobre las investigaciones en competencia cultural en los profesionales de salud en España. Revista de Enfermería, Barcelona, 40:60-67.

RENGEL, Carmen. 2017. La batalla contra la mutilación genital femenina en España. In: https://www.huffingtonpost.es/2017/02/06/mutilacion-genital-espana n 14592178.html (acessado em 25 de janeiro de 2020).

REYONOSO, Carlos (comp.). 1996. El surgimento de la antropología posmoderna. Barcelona, Gedisa.

RISECO PÉREZ, Santiago. 2019. En España hay 18.000 niñas expuestas a la mutilación genital.

http://www.rtve.es/noticias/20190206/espana-hay-18000-ninas-expuestas-mutilacion-genital/ 1879920.shtml (acessado em 25 de janeiro de 2020).

SERBIN, Sylvia. 2015. Reinas de África y las heroinas de la diáspora negra. Barcelona, Wanáfrica ediciones.

WERUNGA, Jane; REIMER-KIRKHAM, Sheryl; EWASHEN, Carole. 2016. A decolonizing methodology for health research on female genital cutting. Advances in Nursing Science, Connecticut, 39(2):150-164. 